\title{
Kifoskolyozlu Hastada Fiberoptik Bronkoskopi İle Perkuitan Trakeostomi Uygulaması: Olgu Sunumu
}

\author{
Percutaneous Tracheostomy with Fiberoptic Bronchoscopy \\ in a Patient with Kyphoscoliosis: Case Report \\ Fatih Şahin, Alkan Kibar \\ Sakarya Yenikent Devlet Hastanesi, Anesteziyoloji Ve Reanimasyon Kliniği, Sakarya, Türkiye \\ Yazışma Adresi / Correspondence: \\ Fatih Şahin \\ Sakarya Yenikent Devlet Hastanesi, Anesteziyoloji Ve Reanimasyon Kliniği, Sakarya, Türkiye \\ T: +905062607219 E-mail: tyflfatih16@hotmail.com \\ Geliș Tarihi / Received : 27.12.2019 Kabul Tarihi / Accepted : 01.06.2020 \\ Orcid: \\ Fatih Sahin: https://orcid.org/0000-0002-8501-0675 \\ Alkan Kibar: https://orcid.org/0000-0002-0049-929X \\ ( Sakarya Tip Dergisi / Sakarya Med J 2020, 10(2):322-325) DOI: 10.31832 smj.664493
}

$\ddot{\mathrm{O} z}$

Kifoskolyoz (KS) hastalarında göğüs duvar hareketliliği ve kısıtlı akciğer kapasitelerinden dolayı solunum fonksiyonları bozulmaktadır. Bu tip zor hava yolu olan hastalarda perkütan trakeostomi (PT) uygulaması sırasında fiberoptik bronkoskopi (FOB) kullanımının yaygınlașması gerekmektedir. İleri derecede trakeal deviasyonu olan ve uzun süredir mekanik ventilatörde takip edilen hastaya FOB eşliğinde PT başarılı bir şekilde uygulandı. Bu hastalarda PT işleminin FOB eșliğinde uygulanmasının işlem başarısını artırdığını düșünmekteyiz.

Anahtar bronkoskopi; trakeostomi; mekanik ventilasyon

kelimeler

Abstract

Respiratory functions are impaired in patients with kyphoscoliosis (KS) due to chest wall mobility and limited lung capacity. In patients with this type of difficult airway, the use of fiberoptic bronchoscopy (FOB) should be widespread during percutaneous tracheostomy (PT). FOB-guided PT was successfully applied to the patient who had severe tracheal deviation and had been followed up on mechanical ventilator for a long time. We think that FOB-guided PT in these patients increases the success of the procedure.

Keywords bronchoscopy; tracheostomy; mechanical ventilation 


\section{GIIRIŞ}

Kifoskolyoz (KS) genel popülasyonda \%2-3 oranında görülen omurga eğriliği ve gögüs duvarı deformitesine yol açan kronik bir hastalıktır. Sonuç olarak göğüs duvarı uyumunun azalması nedeniyle kısıtlı akciğer kapasitelerinden dolayı solunum fonksiyonu bozulmaktadır. ${ }^{1}$

Yoğun bakım üniteleri (YBÜ)'nde uzun süreli yapay solunum gerektiren kritik hastalarda hava yolu tipik olarak perkütan trakeostomi (PT) ile sağlanır. Bazı hastalar için, trakeostomi bölgesini anatomik işaretlere dayanarak belirlemek zordur. Fiberoptik bronkoskop (FOB) bu hastalarda YBÜ’de yaygın olarak kullanılır., ${ }^{2,3}$ FOB kullanımıyla trakea içinde, bronkoskopi ışığının translüminasyonu sayesinde trakeostomi açılması planlanan alan saptanabilir. FOB’un kamerası dinamik görüntü sağladığından uygulayıcı PT prosedürünü rahatlıkla izleyebilir. ${ }^{4}$

\section{OLGU SUNUMU}

74 yaşında cobb açısı $68^{\circ}$, vertebra rotasyonu evre 3 olan ileri derece KS'lu erkek hasta oksipotemporal subakut infarkt ve pnömoni tanıları ile YBÜ'nde takip edilirken solunum fonksiyonlarının yetersiz kalmasından dolayı tedavisinin 16. gününde orotrakeal entübasyon ile mekanik ventilatör (MV)'e bağlandı. Posteroanterior akciğer grafisinde (PAAG) ileri derecede skolyozu olduğu ve trakeanın orta hattan kaydığı görüldü (Resim 1).

Antibiyoterapisinin bitmesi ve pnömoni tablosu gerilemesine rağmen hastanın MV ihtiyacı devam etti. MV desteğinin uzun süreceği öngörüldüğünden 21. günde hastaya trakeostomi işleminin yapılmasına karar verildi. Yapılan konsültasyonlar sonucunda hastanın tiromental mesafenin $3 \mathrm{~cm}$ olması, kısa ve kalın boyun, baş fleksiyon-ekstansiyonun olmaması ve başın lateralize postüründen dolayı cerrahi trakeostomi işleminin zor olacağı düşünülerek PT'ye karar verildi. Hasta yakınından PT için yazılı onam alındı. Hastanın ilk endotrakeal entübasyonu işleminde zor maske ventilasyonu ve zor entübasyon ile karşılaşılmamış olup işlem direkt laringoskopi ile gerçekleştirilmişti.

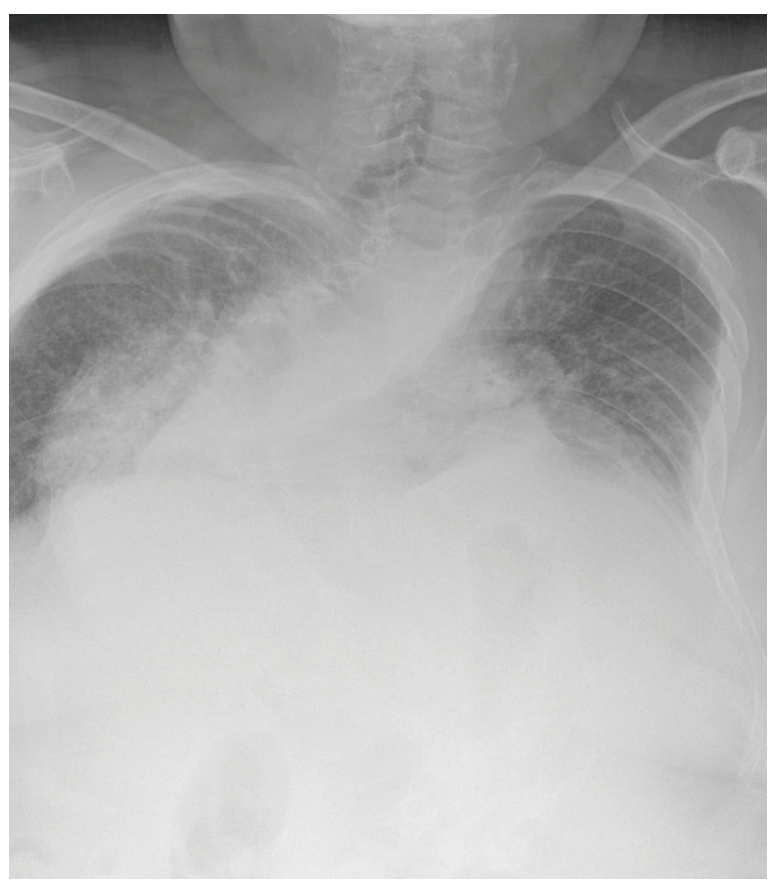

Resim 1. Posteroanterior akciğer grafisinde trakea deviasyonu görüntüsü

Cormack lehane skoru 2 olarak değerlendirilmişti ve herhangi bir zor hava yolu gereci kullanılmamıştı. Ancak hastanın mevcut anatomik deformitelerinden dolayı işlem esnasında oluşabilecek zor hava yoluna karşı direkt laringoskop dışında LMA Fastrach ve Hugemed VL3R Videolaringoskop da hazır olarak bulunduruldu. Propofol 120 $\mathrm{mg}$, fentanyl hidroklorür $75 \mathrm{mcg}$, rokuronyum bromür 50 mg intravenöz uygulanarak genel anestezi indüksiyonu yapıldı. Supin pozisyonda, omuz altını yükseltecek şekilde silikon yastık yerleştirildi fakat baş ekstansiyonu sağlanamadığından dolayı trakea halkaları arasında iğne giriş yerinde genişleme görülemedi. Entübasyon tüpü balonu vokal kord dışında kalacak şekilde $20 \mathrm{ml}$ hava ile şişirildi ve bir yardımcı tarafından elle sabitlenerek MV'ye bağlandı. PT işlemi öncesinde FOB tüp içerisinden ilerletilerek trakea incelendi; vokal kord ile karina arasındaki mesafenin çok kısa olduğu, trakea deviasyonu bulunduğu ve uzun süreli entübasyona bağlı mukozal hasar geliştiği görüntülendi. FOB ucu endotrakeal tüpün alt ucuna gelecek şekilde yerleştirildi ve trakeal halkalar normal anatomik yapının 
dışında olduğundan iğne giriş yerine karar vermek için FOB ışı̆̆ının translüminasyonundan faydalanarak iğne giriş yeri belirlendi. İçi serum fizyolojik dolu iğne ve etrafındaki plastik kanül 2-3. trakeal halka arasından negatif aspirasyonla hava gelene kadar trakeaya dik olarak ilerletildi ve hava geldiğinde ilerlemesi durduruldu. İğne ve plastik kanül FOB ile görüntülenirken iğne dışarı alındı ve plastik kanül içinden kılavuz tel yerleştirilerek telin karinaya doğru ilerlediği izlendi (Resim 2).

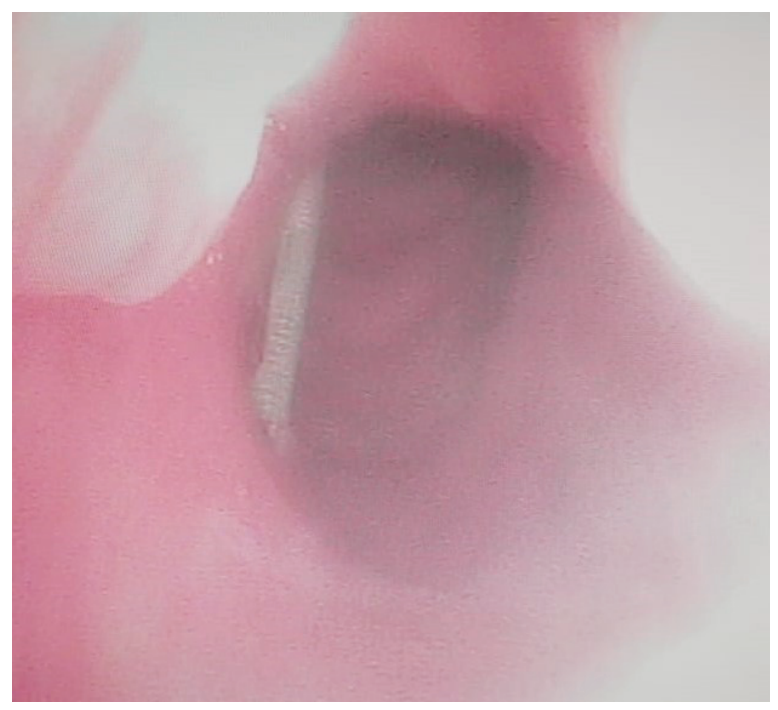

Resim 2. Kılavuz telinin trakea içinde karinaya doğru yönlenişi

Plastik kanül çıkarılarak klavuz teli üzerinden plastik dilatatör yerleştirilerek cilt, cilt altı ve trakea dilate edildi. Daha sonra delikli forceps ile 8 numara trakeostomi kanülü girecek büyüklükte giriş yeri genişletilerek trakeostomi kanülü yerleștirildi ve MV trakeostomi kanülüne bağlandı. FOB ile trakeostomi kanülü içinden yerleşimi doğrulandı ve kanama olmadığı görüntülendikten sonra işlem sonlandırıldı. İşlem sonrası hemen PAAG’si çekilerek herhangi bir komplikasyon olmadığı teyit edildi. Hastanın yasal vasisinden makalenin yayınlanması ile ilgili bilgilendirilmiş gönüllü onam alınmıştır.

\section{TARTIŞMA}

Kifoskolyoz, ilerleyici hipoventilasyon, hiperkapni ve kro- nik solunum yetmezliğine yol açan, azalmış göğüs duvar hareketleri ve bozulmuş solunum mekaniği ile karakterize bir hastalıktır. ${ }^{5}$ Akut alevlenmeler YBÜ yatı̧ları sırasında hastaların invaziv ya da non-invaziv solunum desteği almasina neden olur. Bizim olgumuzda ileri derece de KS’a bağlı göğüs duvar hareket bozukluğu mevcuttu ve gelişen akut bakteriyal pnömoni nedeniyle antibiyoterapi aldı.

Bazı yayınlarda, mekanik ventilasyon için trakeostomi gereken hastalarda PT altın standart olarak kabul edilmektedir. ${ }^{6}$ PT bronkoskopik görüntüleme olmadan gerçekleştirilebilse de yatak başı PT işlemi genellikle bronkoskopi kılavuzluğunda gerçekleştirilmektedir.7 Delaney ve ark. yaptığı randomize kontrollü çalışmada PT uygulanan hastalar ile ameliyathanede yapilan cerrahi trakeostomi karşılaştırıldığında PT'de daha az kan kaybı ve mortalite olduğunu göstermiştir. ${ }^{8}$ Bronkoskopik rehberlik trakeostominin paratrakeal yerleşim riskini en aza indirmekte ve özefageal perforasyon riskini önleyebilmektedir. ${ }^{9}$ YBÜ’de en iyi sağkalım oranlarının nöromusküler hastalıklar ve KS hastalarında olduğu gösterilmiştir. ${ }^{10}$ Trakeostomi için ana endikasyon kritik hastalarda uzun süreli hava yolu erişim ihtiyacıdır. YBÜ'deki trakeostomilerin çoğu çeşitli nedenlerden dolayı zaten entübe vaziyette mekanik ventilatör tedavisi alan hastalar üzerinde yapılır. Trakeostomi daha güvenli bir havayolu imkanı sağlar ve kazara ekstübasyon ihtimalini azaltır. Hastanın ileri derecede KS, trakeal deviasyon varlığı, kısa boynu ve baş fleksiyon ekstansiyon hareketleri olmamasından dolayı cerrahlar tarafından cerrahi trakeostomi işlemi yapılmadı. PT, FOB eşliğinde başarılı bir şekilde uygulandı ve herhangi bir komplikasyon gözlenmedi.

\section{SONUÇ}

Anatomik işaret noktaları bozulmuş ve pozisyon vermekte güçlük çekilen bu tip hastalarda PT’de FOB kullanımının sadece komplikasyonları azaltmakta kalmayıp başarı şansını artırabildiği ve bu tip hastalarda kullanılmasının faydalı olduğu düşüncesindeyiz. 
Sakarya Tip Dergisi 2020;10(2):322-325

\section{Kaynaklar}

1. Smyth RJ, Chapman KR, Wright TA, Crawford IS, Rebuck AS. Pulmonary function in adolescent with mild idiopathic scoliosis. Thorax 1984;39:901-904.

2. Vargas M, Sutherasan Y, Antonelli M, Brunetti I, Corcione A, Laffey JG et al. Tracheostomy procedures in the intensive care unit: an international survey. Crit Care 2015;19:291.

3. Grensemann J, Eichler L, Kahler S, Jarczak D, Simon M, Pinnschmidt HO et al. Bronchoscopy versus an endotracheal tube mounted camera for the periinterventional visualization of percutaneous dilatational tracheostomy-a prospective, randomized trial (VivaPDT). Crit Care 2017;21:330

4. Ravi PR, Vijay MN. Real time ultrasound-guided percutaneous tracheostomy: is it a better option than bronchoscopic guided percutaneous tracheostomy?. Med J Armed Forces India 2015;71:158-164.

5. Bergofsky EH. Respiratory failure in disorders of the thoracic cage. Am Rev Respir Dis 1979;119:643-669.
6. Kornblith LZ, Burlew CC, Moore EE, Haenel JB, Kashuk JL, Biffl WL et al. One thousand bedside percutaneous tracheostomies in the surgical intensive care unit: time to change the gold standard. J Am Coll Surg 2011;212:163-170.

7. Wang SJ, Sercarz JA, Blackwell KE, Aghamohammadi M, Wang MB. Open bedside tracheotomy in the intensive care unit. Laryngoscope 1999;109:891-893.

8. Delaney A, Bagshaw SM, Nalos M. Percutaneous dilatational tracheostomy versus surgical tracheostomy in critically ill patients: a systematic review and meta-analysis. Crit Care 2006; 10:R55.

9. Reibel JF. Tracheostomy. Respir Care 1999;44:820-823.

10. Aksoy E, Ocakl B. Long-Term Survival of Patients with Tracheostomy Having Different Diseases Followed up in the Respiratory Intensive Care Unit Outpatient Clinic: Which Patients are Lucky? Turk Thorac J 2019;20:182-187. 